\title{
Influence of the Ions in Pore Solution and around the Steel Bar on Corrosion of Steel in BFS and FA Mortars ${ }^{\dagger}$
}

\author{
by
}

\author{
Nobuaki Otsuki ${ }^{*}$, Anita II Odchimar ${ }^{* *}$ and Tsuyoshi Sarto *
}

\begin{abstract}
This research investigated the corrosion behavior of steel in mortars with $40 \%$ blast furnace slag cement replacement and $20 \%$ fly ash cement replacement to ordinary Portland cement, considering the concentrations of chloride and other ions present in the mortars saturated pores and around the steel bar. Three methods were used to extract solutions from mortars wherefrom ions were measured. Results showed that reinforcing bar corrosion activity was lower for FA mortars than BFS mortars; and both having better corrosion resistances than mortars with only OPC as binder. Correspondingly, $\mathrm{Cl}^{-}$contents in pore solutions followed the trend $\mathrm{OPC}>\mathrm{BFS}>\mathrm{FA}$ mortars. The $\mathrm{Cl}^{-} / \mathrm{OH}^{-}$ contents in the solutions obtained from around the steel bar correspond to the mortars corrosion behavior, signifying the influence of $\mathrm{Cl}^{-}$and $\mathrm{OH}^{-}$on corrosion and the greater importance of investigating the ions around the bar than that in the pore solutions of the bulk mortar. Moreover, significant differences in $\mathrm{Cl}^{-}$contents were measured using the 3 methods of solution extraction, which validate that the variations in the method of solution extraction account for the inconclusive $\mathrm{Cl}^{-}$threshold values for reinforcing bar corrosion published in literatures.
\end{abstract}

Key words : Reinforcing bar corrosion, Chloride threshold value, Fly ash cement, Blast furnace slag cement

\section{Introduction}

Blended cements with blast furnace slag (BFS) and fly ash (FA) are now in popular use. Their production has even exceeded that of ordinary Portland cement (OPC) in Asia and Europe. The popularity owes to the benefits in economy as well as in the environment, from reduction in wastes to reduction in $\mathrm{CO}_{2}$ emissions. Despite these, there is still no general agreement in their performances with regard to corrosion of embedded steel bars. Reinforcing bar corrosion is the most common durability problem that concrete structures are facing. Some studies reported that the partial substitution of BFS and FA to OPC improves resistance to corrosion, ${ }^{1), 2)}$ while still others reported otherwise. ${ }^{3), 4)}$

Chlorides are considered the major culprit for reinforcing bar corrosion. Chloride ions are present in seawater; making the structures exposed to the marine environment susceptible to chloride-induced corrosion. However, from literatures, there is inconclusive data about chloride threshold value $\left(\mathrm{C}_{\text {crit }}\right)$ - the $\mathrm{Cl}^{-}$content that initiates steel depassivation or the breakdown of the passive oxide film present around the steel. ${ }^{3)}$ This insoluble film $(\sim 0.01 \mu \mathrm{m})$ forms when the metal reacts with oxygen, and provides the steel isolation from the surrounding solution, thus slowing down anionic dissolutions. But with the presence of certain concentration of chloride ions $\left(\mathrm{C}_{\text {crit }}\right)$, ferrous oxide films can be broken down into a soluble complex that does not provide protection. Many $\mathrm{C}_{\text {crit }}$ values have been provided in literatures. ${ }^{3), 12)}$

Inconclusive data is attributed to the unsuitability of the experimental procedures used, one of which is the method of extracting pore solutions wherefrom free $\mathrm{Cl}^{-}$ contents are measured. Free $\mathrm{Cl}^{-}$are those not bound to the cement hydration products, and are generally recognized to be the only form which induces corrosion.

The existing methods of solution extraction obtain the pore solutions from the bulk concrete, though some studies showed that the microstructure of the steel-paste interface differs from the bulk mortar ${ }^{5)}$; thus the free $\mathrm{Cl}^{-}$ measured from pore solutions may not be indicative of the actual content affecting the steel.

In the pursuit to eliminate these gaps in the research field, this present study aims to fulfill the following objectives : First, to investigate the corrosion behavior of steel in BFS and FA mortars. Second, to investigate the ion concentration in the pore solutions of the bulk mortar through pore water expression and water-soluble leaching, and around the steel bar through a method of washing the bar developed by Otsuki (1993). ${ }^{6)}$ Taking these ions as bases, this research also aims to obtain the correlation between the solution extraction methods, and the influences of the ion concentrations on steel corrosion behavior.

Significant differences in measured $\mathrm{Cl}^{-}$concentrations would validate that the ions around the steel bar are more important to corrosion, and that the difference in the methods of solution extraction is one of the reasons for the inconclusive $\mathrm{Cl}^{-}$threshold values published in literatures.

\section{Experimental Method}

\section{1 Materials used}

Mortar specimens have the configuration of $\phi 50 \times 100$ $\mathrm{mm}$. Three types of binders were used : (a) $100 \%$ OPC, (b) $\mathrm{OPC}+40 \% \mathrm{BFS}$ replacement, (c) $\mathrm{OPC}+20 \% \mathrm{FA}$ replacement. Reinforcements were $\phi 9 \times 50 \mathrm{~mm}$ SD295A ordinary carbon steels. The material properties are 
shown in Table 1 to 2 . Distilled water, not containing uncounted $\mathrm{Cl}^{-}$content, and natural river sand were used in the mix.

\subsection{Mixing, curing and exposure condition}

The water/cement and sand/binder were 0.55 and 2.0, respectively. Chloride ions were internally added during the mixing with amounts of $0,0.5,1.0$ and $2.0 \%$ per binder weight. Table 3 shows the details of mix proportions. Specimens were moist cured in the molds for 24 hours using wet burlaps. After, they were submerged in distilled water at $20^{\circ} \mathrm{C}$ for the whole 3-month exposure duration.

\subsection{Methods of corrosion monitoring}

2.3. 1 Corrosion current density, $\boldsymbol{I}_{\text {corr }}$ Steel corrosion activity can be deduced from $I_{\text {corr }}$ High $I_{\text {corr }}$ means high corrosion activity. $I_{\text {corr }}$ was measured at certain intervals within the 3-month exposure period using AC impedance method with a Corrosion Monitor (CT-8, Riken Denshi Co., Ltd). After measurement, the corrosion current density was calculated through Equation (1).

$$
I_{\text {cor }}=\frac{K}{R_{p} A}
$$

where $I_{\text {corr }}=$ corrosion current density of steel $\left(\mathrm{A} / \mathrm{cm}^{2}\right)$, $R_{\mathrm{p}}=$ polarization resistance $(\Omega), A=$ surface area of rebar $\left(\mathrm{cm}^{2}\right)$, and $K=0.0209(\mathrm{~V})$, the Stern-Geary constant for carbon steel. ${ }^{7)}$

2.3.2 Steel passivity Steel passivity refers to the presence of approximately $10 \mathrm{~nm}$ thick passive oxide film around the steel bar that isolates it from surrounding moisture. Once the passive film is broken, oxygen and water can then freely react with iron, commencing the corrosion reaction.

Steel passivities of specimens were interpreted from anodic polarization curves obtained from a technique of

Table 1 Chemical and physical properties of binders.

\begin{tabular}{|c|c|c|c|c|c|c|c|c|c|}
\hline & \multicolumn{7}{|c|}{ Chemical Composition (mass\%) } & \multirow{2}{*}{\multicolumn{2}{|c|}{$\begin{array}{l}\text { Specific Fineness" } \\
\text { gravity }\left(\mathrm{cm}^{2} / \mathrm{g}\right)\end{array}$}} \\
\hline & $\mathrm{SiO}_{2}$ & $\mathrm{Al}_{2} \mathrm{O}_{3}$ & $\mathrm{Fe}_{2} \mathrm{O}_{3}$ & $\mathrm{CaO}$ & $\mathrm{MgO}$ & $\mathrm{SO}_{3}$ & $\mathrm{Na}_{2} \mathrm{O}$ & & \\
\hline $\mathrm{PC}$ & 20.38 & 5.18 & 3.37 & 63.96 & 1.88 & 2.24 & 0.40 & 3.16 & 3450 \\
\hline FA & 3.18 & 31.69 & 4.27 & 1.0 & 0.57 & 0.20 & 0.20 & 2.80 & . \\
\hline $\mathrm{FS}$ & 33.61 & 14.27 & 0.41 & 44.35 & 6.05 & 1.70 & 0.24 & 2.19 & 4533 \\
\hline
\end{tabular}

Table 2 Chemical composition of steel. (\%)

\begin{tabular}{c|cccccc}
\hline & $\mathrm{Mn}$ & $\mathrm{P}$ & $\mathrm{S}$ & $\mathrm{Si}$ & $\mathrm{C}$ & $\mathrm{Fe}$ \\
\hline SD295A & 0.65 & 0.32 & 0.46 & 0.12 & 0.18 & 98.27 \\
\hline
\end{tabular}

the same name. The test is conducted using a potentiostat (HZ-3000 by Hokuto Denko). The steel's potential is shifted from its natural value to the passive oxide film breakdown potential, or a value of $+1 \mathrm{~V}$, with scan rate of $1 \mathrm{mV} / \mathrm{s}$. The resulting anodic polarization curve is graded based on a system develop by Otsuki et. al. (see Figure 1). ${ }^{6)}$ Grade of 5 means excellent passivity and 0 means no passivity.

Steel passivities were measured at age 3 months of the specimens. $\mathrm{Ag} / \mathrm{AgCl}$ reference electrode was used in the measurements.

\subsection{Methods of solution extraction}

Solutions were extracted from the mortar specimens; and from these, concentrations of $\mathrm{Cl}^{-}, \mathrm{OH}^{-}$and other ions were measured. $\mathrm{Cl}^{-}$destroys the passive oxide film of the steel, while high $\mathrm{pH}$ stabilizes the film. The $\mathrm{OH}^{-}$concentration required to maintain passivation is not a constant value, but varies with the presence of other ions. ${ }^{8)}$

The methods of solution extraction are the following :

2.4.1 Pore water expression (PWE) Pressure of $250 \mathrm{MPa}$ was applied to a steel apparatus containing the cylindrical mortar specimen to squeeze out the pore solutions. This method was detailed in the paper of Barneyback, 1981. ${ }^{9)}$

2.4.2 Water soluble leaching (WS) The method complies with JCI SC4 ${ }^{10)}$ where mortar powder is digested in water for 30 minutes at $50^{\circ} \mathrm{C}$. The leached solution contains the water-soluble chlorides which approximate the free chlorides in the pore solution.

2.4.3 Washing of bar method This is a relatively new method which employs the simple procedure of washing the steel bar devised by Otsuki et. al. ${ }^{6}$ as shown in Figure 2. To improve the dissolution of ions to the wash liquid, the procedure was modified ; the steel

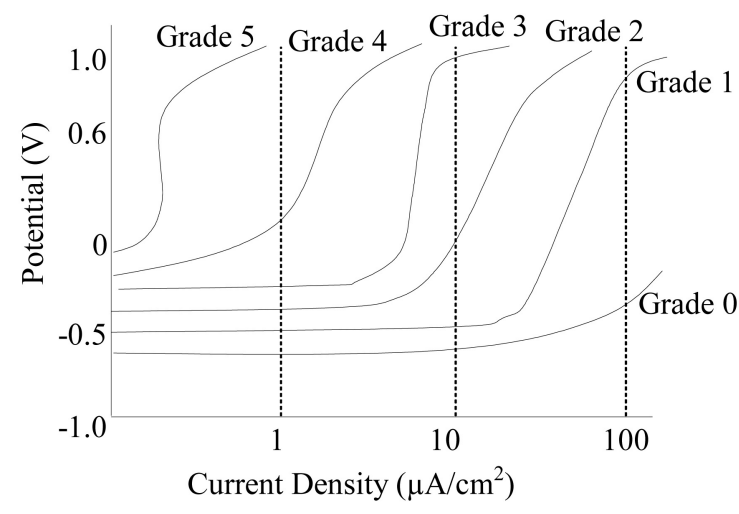

Fig. 1 Concept of passivity grades.

Table 3 Mix proportions.

\begin{tabular}{c|c|cccccc}
\hline \multirow{2}{*}{$\begin{array}{c}\text { Specimen } \\
\text { Label }\end{array}$} & \multirow{2}{*}{ Binder ratio } & \multicolumn{5}{|c}{ Unit Weight $\left(\mathrm{kg} / \mathrm{m}^{3}\right)$} \\
\cline { 3 - 8 } & & Water & OPC & FA & BFS & Sand & Cl- $^{-}(0,0.5,1.0,2.0 \%)$ \\
\hline OPC & $100 \%$ OPC & 337.46 & 613.57 & - & - & 1227.13 & $0,3.07,6.14,12.27$ \\
FA & OPC:FA 80:20 & 333.23 & 484.70 & 121.17 & - & 1211.74 & $0,3.03,6.06,12.12$ \\
BFS & OPC:BFS 60:40 & 334.36 & 364.76 & - & 243.17 & 1215.86 & $0,3.04,6.08,12.16$ \\
\hline
\end{tabular}




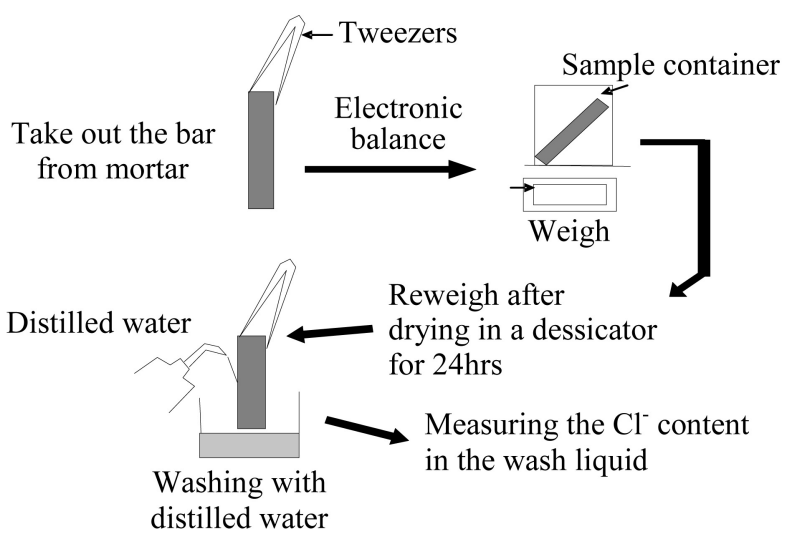

Fig. 2 Extraction of solution around the bar.

was let stayed in the wash liquid for 24 hours under $50^{\circ} \mathrm{C}$. Ion concentrations were measured from the wash liquor after.

\subsection{Measuring ion concentration}

The concentrations of $\mathrm{Cl}^{-}, \mathrm{OH}^{-}$and other ions were measured from the extracted solutions. Ion chromatography for $\mathrm{Cl}^{-}$, $\mathrm{pH}$ meter for $\mathrm{OH}^{-}$, and Induced Coupled Plasma (ICP) for the other ions were used.

\subsection{Chloride-binding capacity investigation}

Only the free $\mathrm{Cl}^{-}$or the chloride ions not bound to the cement hydration products are generally recognized to induce corrosion. Chemical binding of $\mathrm{Cl}^{-}$to cement hydration products results from the reactions between $\mathrm{Cl}^{-}$and $\mathrm{C}_{3} \mathrm{~A}\left(3 \mathrm{CaO} \cdot \mathrm{Al}_{2} \mathrm{O}_{3}\right)$ to form Friedel's salt $(2 \mathrm{CaO}$. $\mathrm{Al}_{2} \mathrm{O}_{3} \cdot \mathrm{CaCl}_{2} \cdot 10 \mathrm{H}_{2} \mathrm{O}$ ) and reaction with $4 \mathrm{CaO} \cdot \mathrm{Al}_{2} \mathrm{O}_{3}$. $\mathrm{Fe}_{2} \mathrm{O}_{3}$ to form a Friedel's salt iron analogue $(2 \mathrm{CaO}$. $\left.\mathrm{Fe}_{2} \mathrm{O}_{3} \cdot \mathrm{CaCl}_{2} \cdot 10 \mathrm{H}_{2} \mathrm{O}\right)$. Friedel's salt peaks, indicative of the chloride-binding capacity of cement hydration products, were investigated through X-ray diffraction.

\section{7 Oxygen permeability investigation}

Rust forms with the reaction of iron with oxygen and hydrogen. Without enough supply of the two specimes, corrosion will not start. Oxygen reacts with hydrogen in the cathodic region of the corrosion cell. The cathodic reaction can be represented by the cathodic polarization curve, which can be obtained through a technique of the same name with the use of a potentiostat.

Reverse of anodic polarization, the steel's potential for cathodic polarization is shifted from its natural potential to further negative, until the limiting current (constant current) is reached. This is usually the current at potential of $-0.86 \mathrm{~V} .{ }^{11)}$ The oxygen permeability is calculated from the limiting current through Equation 2.

$$
J_{0}=\frac{I_{\lim }}{n A F}
$$

where $J_{0}=$ oxygen diffusion rate $\left(\mathrm{mol} / \mathrm{cm}^{2} \mathrm{sec}\right), I_{\mathrm{lim}}=$ limit current (A), $n=$ electron count that reacts with oxygen molecule of $1 \mathrm{~mol}$ in cathodic reaction (=4), $A=$ surface area of rebar $\left(\mathrm{cm}^{2}\right)$, and $F=$ Faraday constant (= $96500 \mathrm{C} / \mathrm{mol})$.

\section{Results and Discussion}

\subsection{Corrosion behavior}

3.1.1 Corrosion current density Referring to Figs. 3 to 6, low corrosion activity based on $I_{\text {corr }}$ were measured for FA and BFS mortars for all amounts of $\mathrm{Cl}^{-}$additions ; their $I_{\text {corr }}$ consistently stayed below $0.02 \mu \mathrm{A} / \mathrm{cm}^{2}$ and $0.04 \mu \mathrm{A} / \mathrm{cm}^{2}$, respectively. While for OPC mortars, $I_{c o r r}$ increase with increase in $\mathrm{Cl}^{-}$addition, with an abrupt increase for the case of $2.0 \% \mathrm{Cl}^{-}$. For all cases of $\mathrm{Cl}^{-}$additions, FA mortars exhibited the lowest corrosion activity. Only OPC mortars with $2 \% \mathrm{Cl}^{-}$showed significant corrosion activity, almost reaching $I_{\text {corr }}$ of $0.1 \mu \mathrm{A} / \mathrm{cm}^{2}$ - the $I_{\text {corr }}$ level that has been reported to indicate start of corrosion. ${ }^{12)}$

3.1.2 Steel passivity Steel passivity results were in good agreement with that of $I_{\text {corr }}$. Only OPC specimens with $2.0 \% \mathrm{Cl}^{-}$exhibited significant steel depassivation, or breakdown of the passive oxide film that isolates the steel from moisture in its surrounding, with very low passivity grade of 1 (see Table 4 )

Figures 7 to 10 show the anodic polarization (AP) curves of the specimens at different amounts of added $\mathrm{Cl}^{-}$. Relatively low current densities were measured for FA and BFS mortars for all cases of $\mathrm{Cl}^{-}$additions.

Table 4 Passivity grades of specimens.

\begin{tabular}{c|cccc}
\hline \multirow{2}{*}{} & \multicolumn{4}{|c}{ Cl content (\% per weight of cement) } \\
\cline { 2 - 5 } & $0 \%$ & $0.5 \%$ & $1.0 \%$ & $2.0 \%$ \\
\hline OPC & 3 & 2 & 3 & 1 \\
FA & 3 & 3 & 3 & 3 \\
BFS & 3 & 3 & 3 & 3 \\
\hline
\end{tabular}

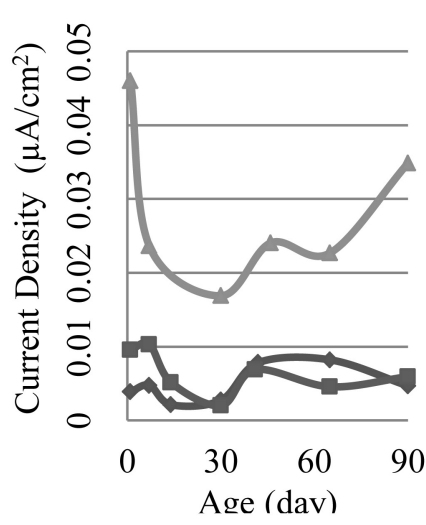

Fig. $3 I_{\text {corr }}$ for $0 \% \mathrm{Cl}^{-}$.

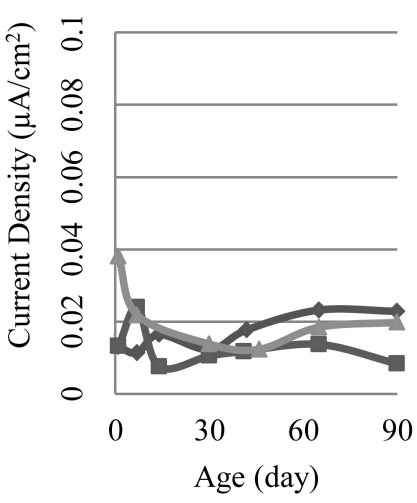

Fig. $5 I_{\text {corr }}$ for $1.0 \% \mathrm{Cl}^{-}$

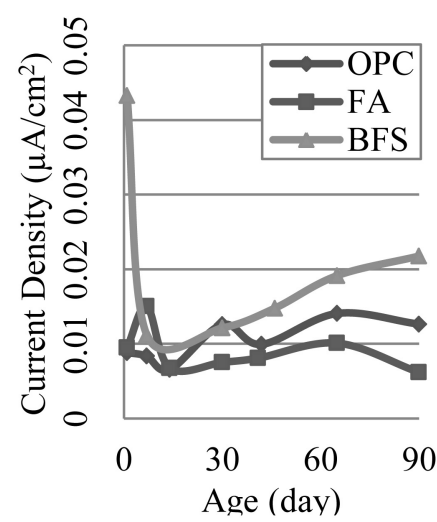

Fig. $4 I_{\text {corr }}$ for $0.5 \% \mathrm{Cl}^{-}$.

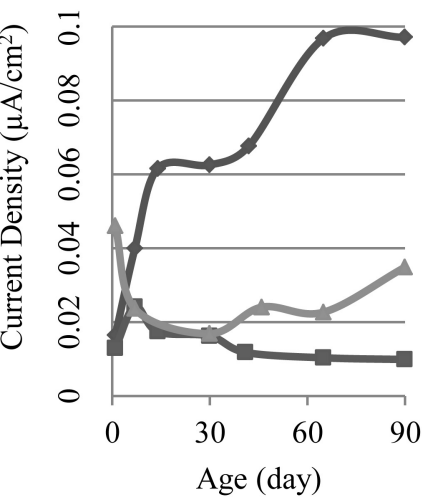

Fig. $6 I_{\text {corr }}$ for $2.0 \% \mathrm{Cl}^{-}$. 


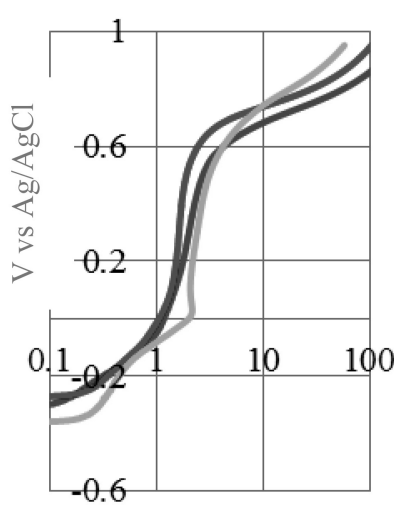

Current Density $\left(\mu \mathrm{A} / \mathrm{cm}^{2}\right)$

Fig. 7 AP for $0 \% \mathrm{Cl}^{-}$.

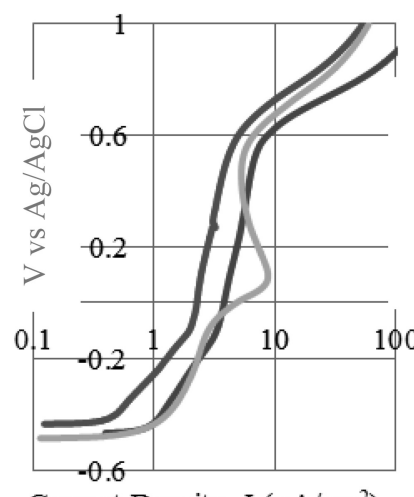

Current Density, I $\left(\mu \mathrm{A} / \mathrm{cm}^{2}\right)$

Fig. 9 AP for $1.0 \% \mathrm{Cl}^{-}$.

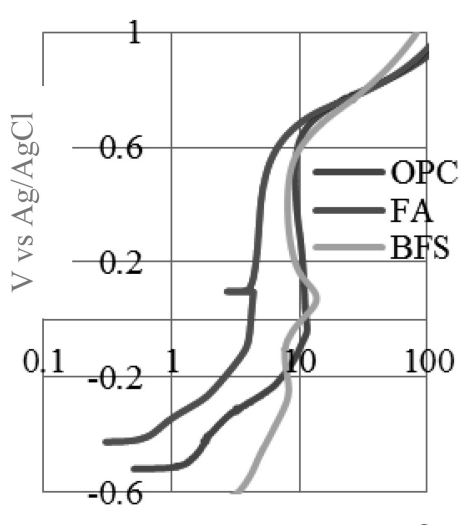

Current Density, I $\left(\mu \mathrm{A} / \mathrm{cm}^{2}\right)$

Fig. 8 AP for $0.5 \% \mathrm{Cl}^{-}$.

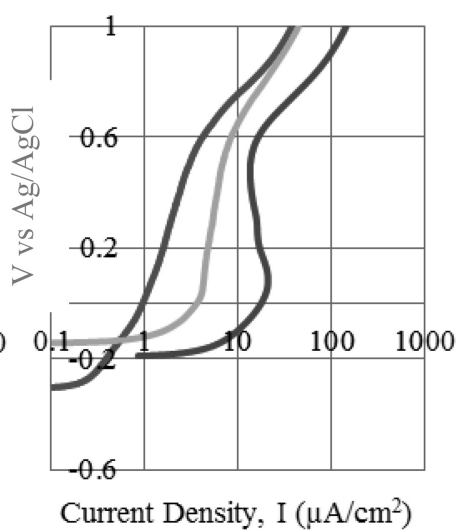

Fig. 10 AP for $2.0 \% \mathrm{Cl}^{-}$.
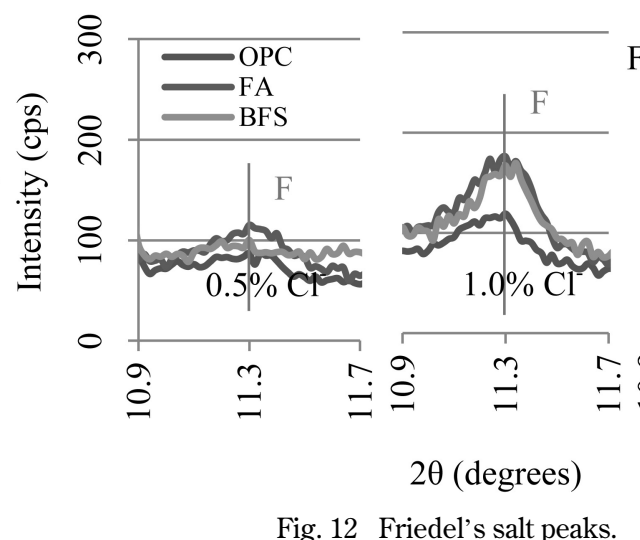

$2 \theta$ (degrees)

Fig. 12 Friedel's salt peaks.

Friedel's salt contents, which is FA $>$ BFS > OPC. This shows that the high chloride binding capacity of cement hydration products of FA mortars resulted to the presence of low free $\mathrm{Cl}^{-}$in their pore solutions. Though free $\mathrm{Cl}^{-}$contents of specimens with $0.5 \% \mathrm{Cl}^{-}$do not correspond to Friedel's salt peaks, variations in free $\mathrm{Cl}^{-}$measured are too small to be significant. High capacity of BFS hydration products to adsorb $\mathrm{Cl}^{-}$may be responsible for their low free $\mathrm{Cl}^{-}$content in this case.

\subsection{Oxygen permeability}

Calculated based on equation 2, FA mortars consistently have the lowest permeability to oxygen for all cases of $\mathrm{Cl}^{-}$additions (see Figure 13). Low supply of oxygen to the steel contributed to the relatively lowest corrosion activity in FA mortars.

\subsection{Ions detected from the pore solutions and their relation to corrosion behavior}

At age 1 month of the specimens, solutions from the pores and around the steel bar were extracted using the methods presented in Section 2.4.

From Figure 14, with concentrations from WS method as the basis, PWE method measured lower free $\mathrm{Cl}^{-}$contents with an average factor of 0.1703 . No trend can be deduced from results of "washing of bar" method. The differences in free $\mathrm{Cl}^{-}$content between those measured from around the bar and those from the bulk mortar is accounted to the differences in the microstructure composition between the two regions in the mortar.

Moreover, WS has a good correlation with PWE with coefficient of determination of 0.9782 , while "washing of bar" method has low correlation with PWE with $\mathrm{R}^{2}$ of 0.4252 (see Figure 15)

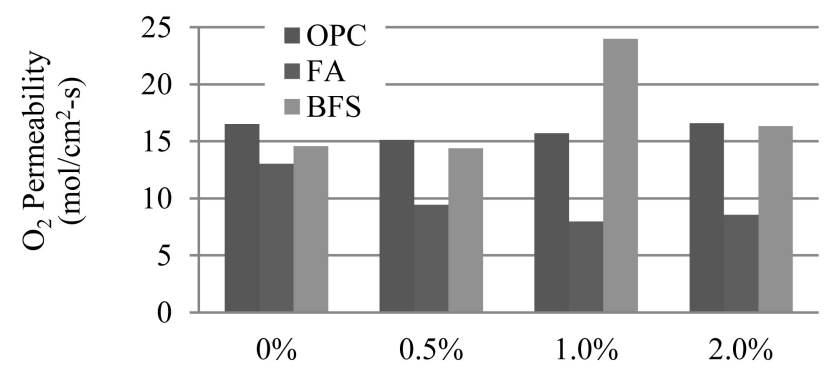

$\mathrm{Cl}^{-}$Added to the Mix

Fig. $13 \mathrm{O}_{2}$ Permeability.

Fig. 11 Free Chloride contents per various $\mathrm{Cl}^{-}$additions to the mix. 


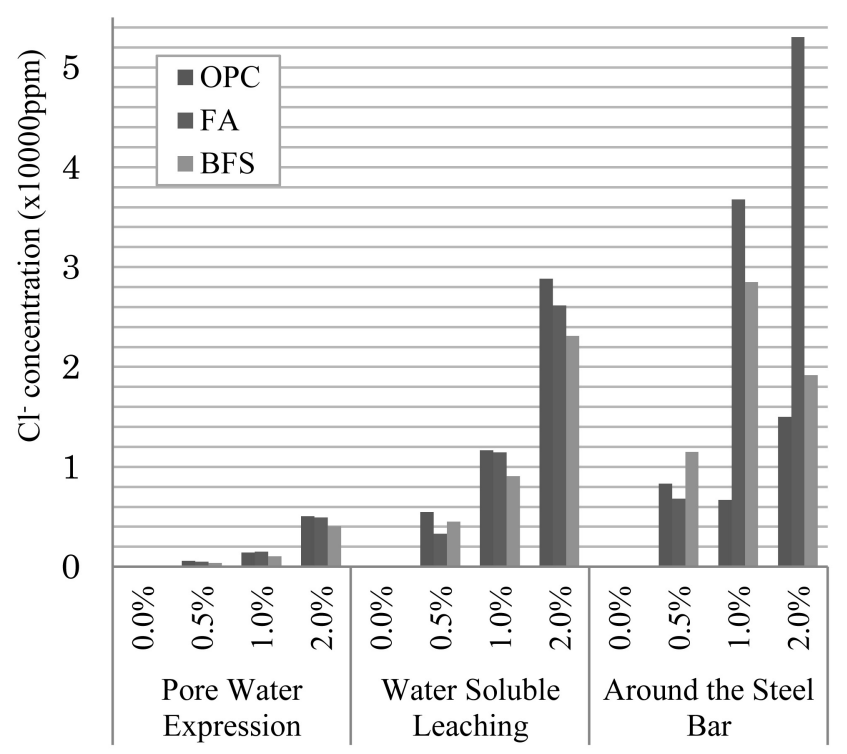

Fig. $14 \mathrm{Cl}^{-}$contents vs. method of solution extraction.

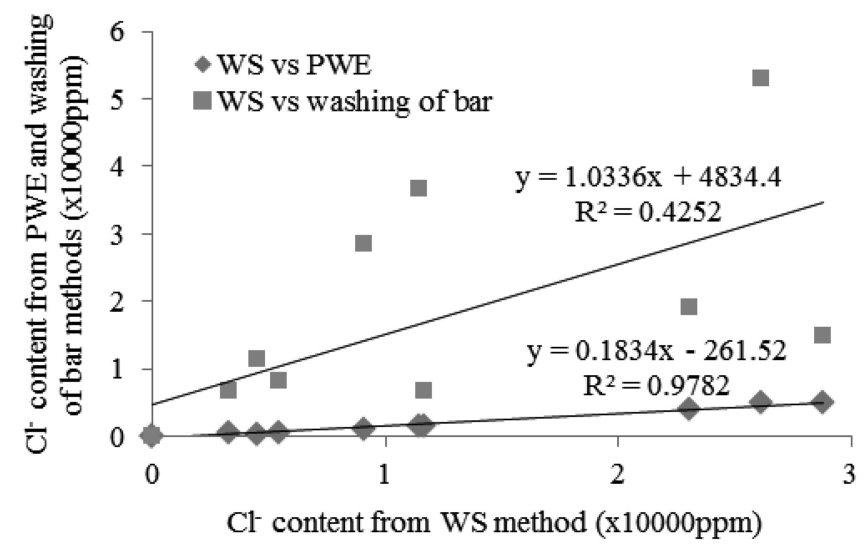

Fig. 15 Correlation of methods based on $\mathrm{Cl}^{-}$contents.

Concentrations of $\mathrm{OH}^{-}, \mathrm{Na}^{+}, \mathrm{K}^{+}, \mathrm{Ca}^{2+}, \mathrm{Si}^{4+}, \mathrm{Al}^{3+}, \mathrm{Mg}^{2+}$, $\mathrm{Mn}^{3+}, \mathrm{Ti}^{4+}, \mathrm{Fe}^{3+}$ and $\mathrm{P}^{5+}$ were detected from the extracted solutions; however, only $\mathrm{OH}^{-}$concentrations showed significant influence to corrosion.

The $\mathrm{Cl}^{-} / \mathrm{OH}^{-}$measured from "washing of bar" (WB) method corresponds to corrosion current density $I_{\text {corr }}$, with OPC having both $I_{c o r r}$ and $\mathrm{Cl}^{-} / \mathrm{OH}$ higher than the other specimens (Figure 16).

Effective passivation of the steel's protective oxide film was obtained with high enough $\mathrm{OH}^{-}$concentration

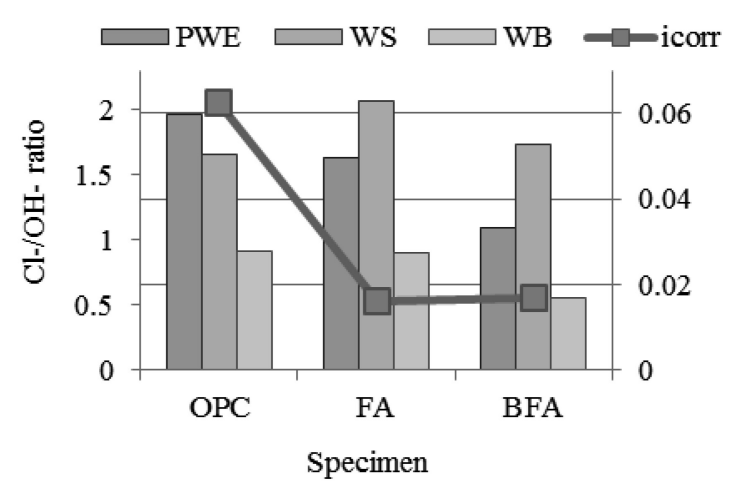

Fig. $16 \mathrm{Cl}^{-} / \mathrm{OH}^{-}$and $I_{\text {corr }}$. around the steel. Though Ghods et al. reported that $\mathrm{pH}$ might not be a determining factor for film quality, ${ }^{13)}$ this present finding indicated that $\mathrm{OH}^{-}$did affect the corrosion behavior, and that the ion concentrations around the bar were more indicative of corrosion behavior than those in the pore solutions of the bulk mortar.

\section{Conclusions}

The corrosion behaviors of steel in BFS and FA mortars, as well as the ions in the pore solutions and around the steel bar were investigated in this research. The following are the conclusions :

(1) Mortars with blended cements BFS and FA had better steel corrosion performances than mortars with only OPC as binder.

Superior steel corrosion performance of FA mortars was attributed to their high chloride binding capacity, which resulted to their having the lowest amount of free $\mathrm{Cl}^{-}$in their pore solutions among the specimens considered. Moreover, they have the lowest oxygen permeability which contributed to their high resistance for corrosion reaction to occur in the reinforcing steel.

While, better corrosion resistance of BFS was contributed by their better chloride binding capacity than OPC mortars.

(2) $\mathrm{Cl}^{-}$concentrations affected the corrosion behavior, as well as the $\mathrm{OH}^{-}$concentrations measured in the solutions obtained from around the steel bar. More free $\mathrm{Cl}^{-}$ were measured from around the bar than from the pore solutions in the bulk mortar.

The $\mathrm{Cl}^{-} / \mathrm{OH}^{-}$of the specimens were in agreement with corrosion activity. Relation to corrosion behavior of other ions measured could not be deduced from the results of this research.

Methods that extract the pore solutions from the bulk mortar (PWE and WS) had good correlation with each other. While the "washing of bar" method that extracted the solution from around the bar has poor correlation with PWE. This indicated that the microstructure composition in the steel-paste interface was likely different than in the bulk mortar, and the ion concentrations from around the bar are more significant to steel corrosion.

\section{References}

1) C. Arya, N. R. Buenfeld and J. B. Newman, "Factors influencing chloride-binding in concrete", Cement and Concrete Research, Vol.20, pp.291-300 (1990).

2) R. K. Dhir, M. A. K. El-Mohr and T. D. Dyer, "Chloride binding in GGBS concrete”, Cement and Concrete Research, Vol.26, pp.1767-1773 (1996).

3 ) U. Angst, B. Elsener. C. K. Larsen and O. Vennesland, "Critical chloride content in reinforced concrete -A review", Cement and Concrete Research, Vol.39, pp.1112-1138 (2009).

4 ) V. K. Gouda and W. Y. Halaka, "Corrosion and corrosion inhibition of reinforcing steel embedded in concrete II", British Corrosion Journal, Vol.5, pp.204-208 (1970).

5 ) L. Yue and H. Shuguang, "The microstructure of the interfacial zone between steel and cement paste", Cement and Concrete Research, Vol.31, pp.385-388.

6) N. Otsuki, S. Nagataki and K. Nakashita, "Evaluation of 
$\mathrm{AgNO}_{3}$ solution spray method for measurement of chloride penetration into hardened cementitious matrix materials", ACI Materials, Journal, Vol.89, pp.587-592 (1992).

7 ) T. Tsuru, R. Maeda and Haruyama, "Corrosion Engineering Technology Report”, Japan Society of Corrosion Engineering, Vol.28, pp.638-644 (1979).

$8)$ A. Bentur, S. Diamond and N. S. Berke, "Steel Corrosion in Concrete : Fundamentals and Civil Engineering Practice", E \& FN Spon (Chapman \& Hall), London, First Edition, p.15 (1997).

9 ) R. S. Barneyback, S. Diamond, "Expression and analysis of pore fluids from hardened cement pastes and mortars", Cement and Concrete Research, Vol.11, pp.279-285 (1981).

10) JCI-SC4, "Kouka concrete chu ni fukumareru enbun-no bunseki-houhou (Result of analysis of chloride quantity in the hardening concrete)", Japan Society of Civil Engineers (2004).

11) S. Nagataki, N. Otsuki, M. Hisada and S. Miyazato, "The experimental study on corrosion mechanism of reinforced concrete at local repair part”, Proceedings of the Japan Society of Civil Engineers 544, Vol.32, pp.109-119 (1996).

12) C. Alonso, C. Andrade, M. Castellote and P. Castro, "Chloride threshold values to depassivate reinforcing bars embedded in a standardized OPC mortar", Cement and Concrete Research, Vol.30, pp.1047-1055 (2000).

13) P. Ghods, O. B. Isgor, G. McRae and T. Miller, "The effect of concrete pore solution composition on the quality of passive oxide films on black steel reinforcement", Cement and Concrete Research, Vol.31, pp.2-11 (2009). 